\section{SIGNIFICANCE OF TRACE ELEMENTS IN PLANTS AND ANIMALS}

$\mathrm{T}$ HE significance of the presence of trace elements in plants and animals was discussed at a meeting of the Association of Applied Biologists held at the Imperial College of Science and Technology, London, on October 4.

Sir Edward Salisbury, in a brief general introduction, said.that he was glad to be present because he had played a part in starting and integrating a series of investigations of mineral deficiencies under the Agricultural Research and Improvement Councils. It may not be generally realized that the crowded plants in a field of wheat are subject to competition and therefore to various deficiencies, which are enhanced if weeds are present. $\mathrm{He}$ pleaded for the researches to be pursued along broader lines than immediately practical ones. As an example, he mentioned the weeds that are known to be efficient in extracting manganese from the soil, and raised the question whether the next crop would benefit from the decomposition of such weeds, or would the deficiency be enhanced as a result of the depletion of the soil of its reserves of available manganese.

Prof. T. Wallace, Long Ashton Research Station, University of Bristol, dealt with the visual diagnosis of mineral deficiencies. The applicability of the method depends on the fact that plants which are deficient in any mineral nutrient develop welldefined and characteristic signs of the shortage in various organs, particularly in the leaves. To provide a basis for using the visual method on crop plants, it is necessary as a first step to produce the visual effects in the various crops and to record the results in a suitable manner. This is done by growing plants under controlled conditions of nutrient supply, usually in sand cultures, to produce the various effects, and afterwards checking the results under field conditions. The visual effects are suitably recorded as colour photographs, the negatives of which can be preserved without appreciable deterioration for several years.

In applying the method to field crops, cognizance is taken of soil conditions, such as texture, drainage, $p H$, dryness and cultural conditions, as the information is often helpful in ruling out certain deficiencies and in pointing to others. The presence of certain pests and diseases may complicate symptoms, and in extreme instances may even rule out the use of the method. Use is also made of indicator plants, that is, plants which are highly susceptible to particular deficiencies and also show characteristic signs of them, such as oats for manganese, sugar beet for boron, potatoes for potassium. Indicator plants may be used, combined with fertilizer and spray treatments, in special indicator plots to determine the likelihood of deficiencies occurring on land of unknown cropping potentialities.

The visual method has the great advantage of requiring no special equipment and is thus particularly suited to survey work, for which it has been widely used. It is also valuable in recording nutrient conditions in field experiments, especially with longterm crops such as fruit. Recently it has been successfully applied to the problem of resolving the injurious factors concerned in the failure of plants on acid soils.
For advisory purposes, visual diagnosis and the chemical tissue test method used together provide a very rapid and effective procedure for solving a wide variety of crop nutritional problems. Details of the method and its use in the field are given in Wallace's "The Diagnosis of Mineral Deficiencies in Plants" (with supplement 1944) (London: H.M. Stationery Office).

American workers have shown that qualitative chemical tests carried out on fresh plant material can be used in the study of fertilizer needs. A technique devised at the Long Ashton Research Station to test quantitatively a number of the easily soluble nutrients in fresh tissues within a short time was described by D. J. D. Nicholas. The method has been successfully used in the diagnosis of mineral deficiencies and toxicities in crop plants, and has served as an invaluable confirmatory test to the visual method. Its value as a diagnostic method is based on the fact that the extractable nutrients from healthy, as compared with unhealthy, plants usually show significant differences for the limiting mineral elements. In this way straightforward deficiencies of potassium, magnesium, calcium, phosphorus, nitrogen and manganese, and excess levels of manganese, chlorine and zinc can be readily confirmed in a short time. The tissue test method is being extended to include other trace elements.

The method involves a special field-sampling technique and preparation of test samples, followed by the extraction of the nutrients from the macerated tissues. Two reagents used for the extraction are (1) Morgan's reagent (glacial acetic acid buffered by means of sodium acetate at $p H .4 .8$; this reagent is specially purified for the sensitive manganese test), (2) hydrochloric acid used in special instances for the extraction of iron and zinc.

The chemical tests used comprise well-known tur. bidity and colour tests, and assessment is made initially by eye. This enables the status of each element to be grouped into high, medium and low categories. These can be fixed more precisely by the use of the Lovibond comparator and standardized colour disks. Nutrient standards have been fixed for a range of economic plants, and a working knowledge of these is essential for accurate diagnostic work. Threshold values for deficiencies have been determ. ined for the various nutrients, which generally coincide with the points of onset of visual signs of the particular deficiencies. In many instances tissue test values give a clue to an impending mineral deficiency or toxicity prior to the onset of visual signs.

A critical study has been made of the seasonal cycle of the extractable nutrients in a variety of crop plants grown under various manurial treatments, in order to determine critical sampling dates in the seasonal cycles of the various nutrient elements.

The correlations obtained between the tissue test results and the nutrient treatment, visual diagnosis and full chemical analysis of the foliage are good. On long-term manurial plots, soil analysis data are usually in accord with tissue test results; but survey work over wide areas has shown that agreement is not always close and further work is necessary.

The tissue test method has proved invaluable for rapid diagnostic work and has played an important part in resolving nutrient disorders in farm and garden crops. It should also be of value in ecological studies and in determining the distribution and trans. location of nutrients in various plant organs. 


\section{No. 4032 February 8, 1947}

The mineral-deficiency team at the East Malling Research Station, near Maidstone, Kent, the work of which was described by Dr. W. A. Roach, has concentrated mainly, but not exclusively, on leaf analysis and plant injection as preliminary methods of diagnosis. But to be of practical value a diagnosis must include a measurement of the effect of curative treatment on yield and quality of erop.

The analytical method is based on a comparison of leaves from unsatisfactory plants with corresponding leaves from plants that are satisfactory from the growers' point of view. At least six elements (iron, manganese, zinc, boron, copper and nickel) occurring in minute amount must be determined in the presence of relatively large amounts of the major nutrient elements. The special methods necessary for this purpose are being evolved. Plant injection methods make possible the treatment of a selected portion of a plant with any desired element, a similar neighbouring part being left untreated for comparison. The part may be of almost any size, from a single inter-veinal area of a leaf to a whole tree. The effect is seen in the course of a week or so.

The first big achievement of the injection method was to find a cure for various 'corky' troubles in apples. These caused the death of whole plantations in western Canada and rendered useless vast amounts of fruit there, in New Zealand and elsewhere. The proof by injection methods that the cause was boron deficiency led in a year to commercial methods of cure by spraying the trees and by applications to the soil. Serious deficiencies of copper in apple and pine trees in Australia and of manganese in cherries in Britain were diagnosed in a similar manner.

Plants are commonly deficient of more than one trace element at a time. Fruit trees in South Africa were deficient of both manganese and zinc. Many trees were dying and still more were barren. The cure of both deficiencies was necessary to restore the trees to full productivity.

Trace-element deficiency may not only accompany potassium deficiency, but also curing the traceelement deficiency seems sometimes to lead to a partial cure of the potassium deficiency, even without the addition of any potassium.

During the War, the methods were used for increasing the yields of arable crops. The cure of symptomless deficiencies of calcium and magnesium diagnosed in potatoes growing on freshly ploughed moorlands in Devon led to an increase of 3,000 tons of potatoes in the following season.

Multiple symptomless deficiencies of manganese, iron, zinc, boron, copper and nickel were proved to be of economic importance in the three crops tested, namely, potatoes, wheat and broad beans, in the marshlands of south Kent. The importance of com. plete diagnosis was illustrated by the fact that spraying potatoes according to diagnosis by symptoms, that is, with manganese, led to no increase in crop, whereas sprays containing manganese and zinc increased the crop from seven to eleven tons per acre, and spraying with all six elements diagnosed by injection led to still greater increases in crop.

The plant in absorbing essential mineral nutrients from the soil also takes up numerous other elements merely because they are brought into solution by the action of its roots, and since plant food is the basis of animal life, the same elements are found in animal tissues. Dr. H. H. Green (Veterinary Laboratory, Ministry of Agriculture, Weybridge) discussed trace elements in relation to the health of livestock.
If an element is found to be locally concentrated in some particular tissue, as, for example, iodine in the thyroid gland, the tendency is to assume a function for it, although it may be long before precise knowledge of that function is gained; but when the quantity of the element is not only exceedingly small but also is distributed throughout the tissues with no known sites of predilection, the impulse is to treat its presence as fortuitous until some instance of apparent absence is met in the form of an obscure deficiency disease, such as the 'pining' of lambs caused by lack of cobalt, or until the effects of unusual excess are shown in the form of a toxicosis such as the 'teart' of cattle in Somerset caused by excess of molybdenum.

Many of the trace elements found in living tissues are apparently inert; for example, nickel, although always present in soil-grown vegetation, does not appear to be an essential animal micro-nutrient, and relatively large amounts are harmless to animals. Some are important to plant physiology but of little consequence in animal economy. Boron is a limiting factor in plant health but, if essential for animal life at all, the smallest amounts ever found in plants are sufficient in the sense that no boron-deficiency disease has ever been recorded in animals. Zinc is certainly required by both plants and animals, and in the case of the latter it is the metallic component of the enzyme 'carbonic anhydrase' found in con. siderable concentration in the red blood corpuseles and other tissues; but the quantities in plant food exceed animal requirements, and no naturally occur. ring zinc-deficiency disease has been encountered.

With other trace elements the position is reversed, and their significance in animal physiology is much greater than in plant economy. Cobalt, if of any significance in plants at all, is required in such small amounts that a pasture may be growing luxuriantly and yet induce emaciation and death in grazing ruminants; while selenium can be tolerated by growing plants in amounts which are exceedingly harmful to animals consuming them.

Trace elements of proved economic importance are: iodine, copper, cobalt, manganese, selenium, molybdenum and fluorine. Lead and arsenic are neither biologically essential nor absorbed through plant roots in quantities injurious to animals. As for arsenic, the danger of cumulative poisoning is much exaggerated. Substantial sub-toxic doses repeatedly administered to sheep are rapidly elimin. ated, and the amounts naturally present in oysters and flat fish, although well above the limit sanctioned by health authorities concerned with arsenic as a food contaminant, are consumed without detriment to human health.

Prof. F. G. Gregory, of the Imperial College of Science and Technology, opened the discussion. $\mathrm{He}$ said that the work of the Research Institute of Plant Physiology on the subject under discussion fell between the field-work described by Dr. Roach and the very fundamental work of Dr. Hill. Use is being made of Dr. Roach's injection methods to provide material on which could be studied the effects of trace elements on various physiological functions of the plant. A start is being made with manganese and the potato, and results so far obtained are encouraging.

Dr. W. G. Ogg, of Rothamsted Experimental Station, said that his experience suggested that Dr. Roach's conclusion, that symptomless deficiencies of economic importance are common, might well apply to nine fields out of ten. 